\title{
Two Dimensional Numerical Model Study on Malaysia KEMAMAN Wharf Project
}

\author{
Meiling Huang1, a, Peng Zhao ${ }^{1, b}$, Xiyu Ouyang 1,c
}

${ }^{1}$ Key Laboratory of Engineering Sediment of Ministry Communications, Tianjin Research Institute for Water Transportation Engineering; No.2618, Xingang Erhao Road, Tianjin, 300456, China

atj_huangmeiling@163.com, coyqingjin@163.com, czhaopeng_tj@tiwte.ac.cn.

Keywords: Two Dimensional, Numerical Model Study, Wharf Project, Current.

Abstract. A two-dimensional numerical model was used to study the current characteristic and deposition around wharf project in Malaysia KEMAMAN. Model study was carried out by using the Commercial software MIKE 21from DHI. The numerical model was calibrated and verified first using measured data and plan layout were loaded to study the current characteristic and deposition after construction. From the study results, the current characteristic and deposition volume were supplied to provide basis for dredging work and ship sailing.

\section{Introduction}

A two-dimensional numerical model was carried out, on the proposed design for the wharf project. The objectives is to analysis the trend of sediment deposition and erosion, including the depositional intensity, the result could provide the scientific reference for the port design. The project site is located at the KEMAMAN port of TERENGGANU, Malaysia.

A location plan is shown in Fig. 1. For implementation of the project, two training walls, two outer breakwater and one navigation channel will be constructed, the layout plan is shown in Fig. 2.

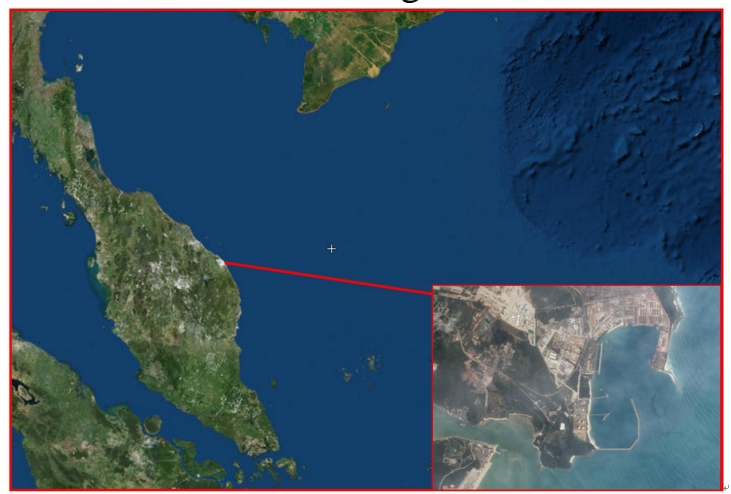

Fig. 1 Location plan of project site

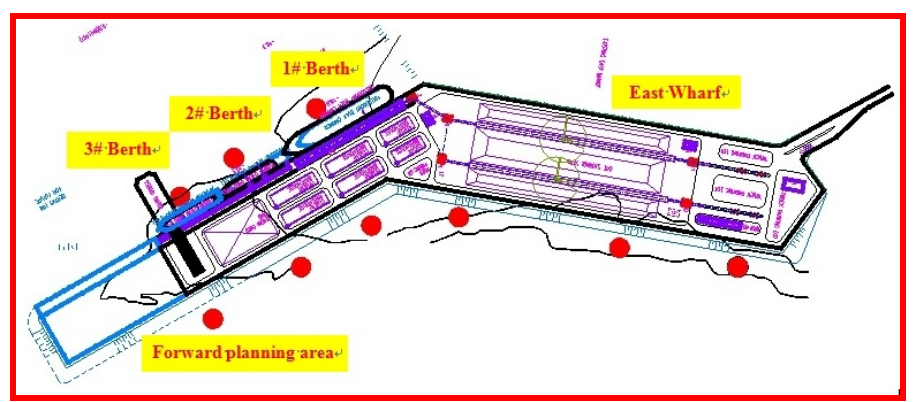

Fig. 2 The layout plan

\section{Natural Conditions}

Tide The mean sea level is $2.24 \mathrm{~m}$. The max tide range is $2.79 \mathrm{~m}$.

Current The current stations CM1\&CM2 were measured from 7/23/2017 to 8/4/2017 (shown in Fig.3). In the spring tide, the maximum speed and the average speed at CM1 are $0.56 \mathrm{~m} / \mathrm{s}, 0.24 \mathrm{~m} / \mathrm{s}$ respectively. The maximum speed and the average speed at CM 2 are $0.69 \mathrm{~m} / \mathrm{s}, 0.29 \mathrm{~m} / \mathrm{s}$ respectively. In the neap tide, the maximum speed and the average speed at CM1 are $0.36 \mathrm{~m} / \mathrm{s}, 0.15 \mathrm{~m} / \mathrm{s}$ respectively. The maximum speed and the average speed at CM2 are $0.53 \mathrm{~m} / \mathrm{s}, 0.19 \mathrm{~m} / \mathrm{s}$ respectively.

Grab Sampling From the analysis result (seen in Fig.4), the median diameters (D50) of the 50 sampling points are in $0.0040 \sim 3.511 \mathrm{~mm}$, and the average value for all the points is about $0.24 \mathrm{~mm}$.

*Corresponding author.

E-mail address: oyqingjin@163.com (Xiyu Ouyang). 
Suspended Sediment Sampling Based on average sediment concentration ranges from 0.006 $\mathrm{kg} / \mathrm{m}^{3}$ to $0.14 \mathrm{~kg} / \mathrm{m}^{3}$, the value reduced from river mouth to the sea.

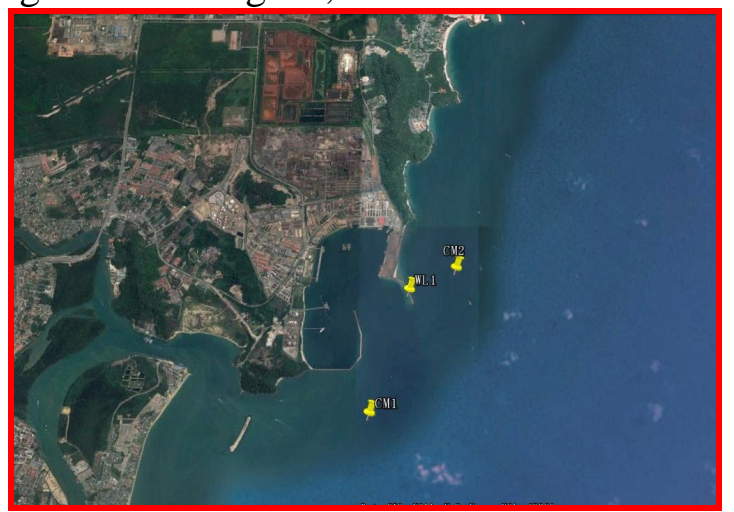

Fig. 3 Positions of survey stations

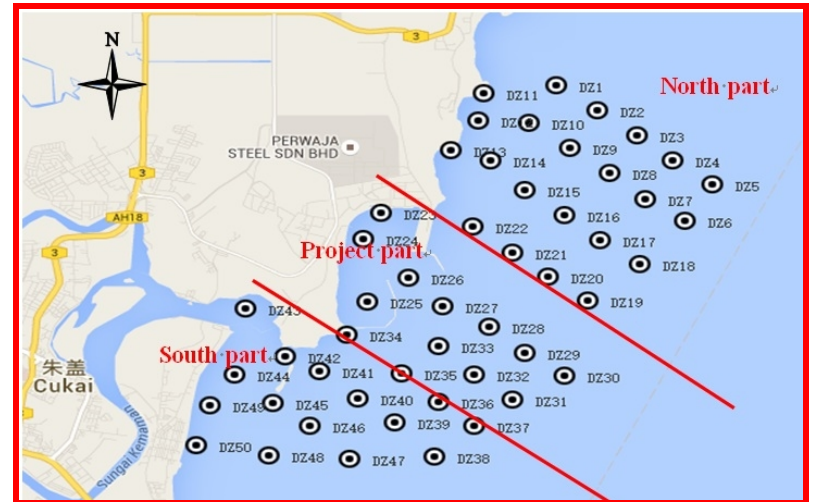

Fig. 4 The distribution for 50 sample station

\section{Basic Equations}

The basic equations of two-dimensional mathematical model of tidal current, includes the continuity equation and momentum equation, the form control equations are as follows:

Continuity equation:

$$
\frac{\partial h}{\partial t}+\frac{\partial h \bar{u}}{\partial x}+\frac{\partial h \bar{v}}{\partial y}=h S
$$

Equations of motion in $\mathrm{x}$ direction and $\mathrm{y}$ direction:

$$
\begin{aligned}
& \frac{\partial h \bar{u}}{\partial t}+\frac{\partial h \bar{u}}{\partial x}+\frac{\partial h \bar{v}}{\partial y}=f \bar{v} h-g h \frac{\partial \eta}{\partial x}-\frac{\partial \rho}{\partial x} \frac{g h^{2}}{2 \rho_{0}}+\frac{\tau_{s x}}{\rho_{0}}-\frac{\tau_{b x}}{\rho_{0}}+\frac{\partial}{\partial x}\left(h T_{x x}\right)+\frac{\partial}{\partial y}\left(h T_{x y}\right)+h u_{s} S \\
& \frac{\partial h \bar{v}}{\partial t}+\frac{\partial h \bar{u}}{\partial x}+\frac{\partial h \bar{v}}{\partial y}=-f \bar{v} h-g h \frac{\partial \eta}{\partial y}-\frac{\partial \rho}{\partial y} \frac{g h^{2}}{2 \rho_{0}}+\frac{\tau_{s y}}{\rho_{0}}-\frac{\tau_{b y}}{\rho_{0}}+\frac{\partial}{\partial x}\left(h T_{x y}\right)+\frac{\partial}{\partial y}\left(h T_{y y}\right)+h u_{s} S
\end{aligned}
$$

The method of estimation by empirical formula is also employed in the research. The formula of estimating deposition for harbor basin which is proposed by Liu Jia-ju in 1988 is used.

$$
P=(1+\psi) \frac{K_{2} \omega S_{1} t}{\gamma_{0}}\left[1-\frac{d_{1}}{2 d_{2}}\left(1+\frac{d_{1}}{d_{2}}\right)\right]
$$

Where, $P$ is annual averaged deposition intensity $(\mathrm{m}) ; \omega$ is setting velocity; $S$ is average suspended sediment concentration $\left(\mathrm{kg} / \mathrm{m}^{3}\right)$, extracted from results of numerical model; $t$ is deposition duration(s), 31536000 (365 day) is used, in estimation of sudden deposition, 86400( 1 day) is used; $r_{0}$ is the dry density of deposition $\left(\mathrm{kg} / \mathrm{m}^{3}\right) ; K_{0}$ is the empirical coefficient; $V_{1}, V_{2}$ is the current velocity before and after project implement $(\mathrm{m} / \mathrm{s})$, extracted from results of numerical model; $d_{1}, d_{2}$ is the water depth before and after project implement $(\mathrm{m} / \mathrm{s})$.

\section{Model Construction}

In order to improve the computational efficiency and ensure enough resolution in project area, unstructured triangular mesh with local refinement is adopted. The mesh chart of the 2-D mathematical model are respectively seen in Fig.5 and Fig.6.The model including the sea area beyond -70 isobaths, from north to south is approximately $140 \mathrm{~km}$, from west to east is approximately $120 \mathrm{~km}$. Model calculation is using local encryption triangular grid, the biggest spacing resolution is $2500 \mathrm{~m}$, and the smallest spacing resolution is $10 \mathrm{~m}$.There are 48747 calculating nodes, and 93434 mesh elements. 


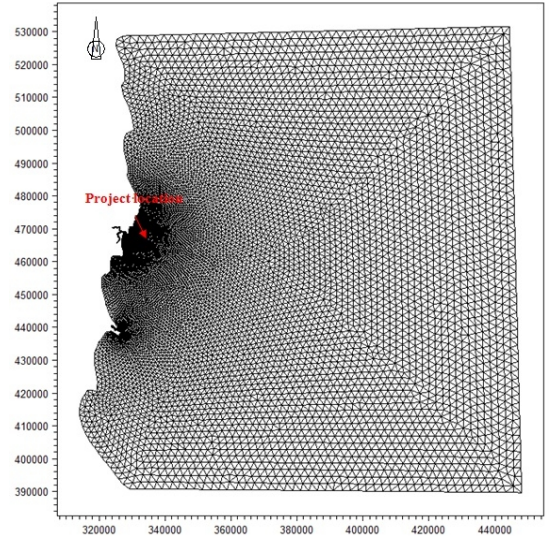

Fig. 5 General mesh of numerical model

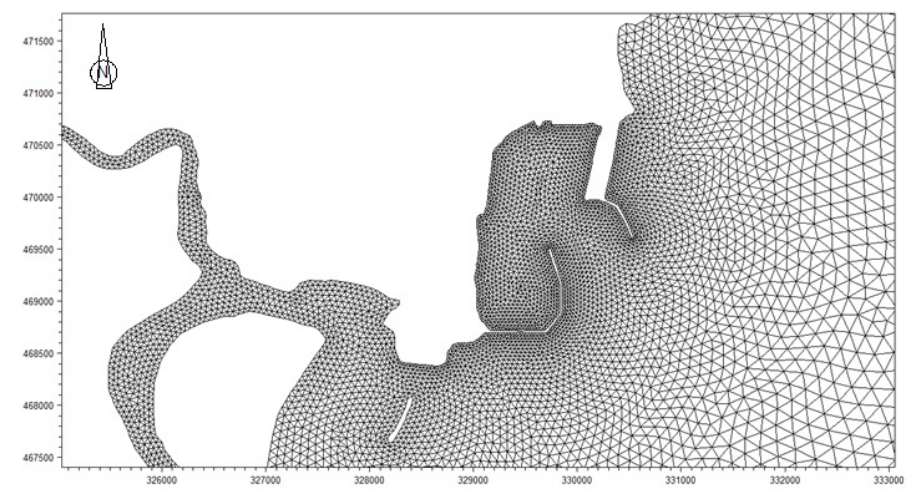

Fig. 6 Local mesh of numerical model

\section{Model Calibration and Verification}

The topography is based on MIK21-CMAP and field measured results, the simulation considered the project have been built. According to the calibration data above in 2017, the results are almost in accordance with JPS Guideline. In the water level calibration, 70\% calculation data meet the JPS Guideline.

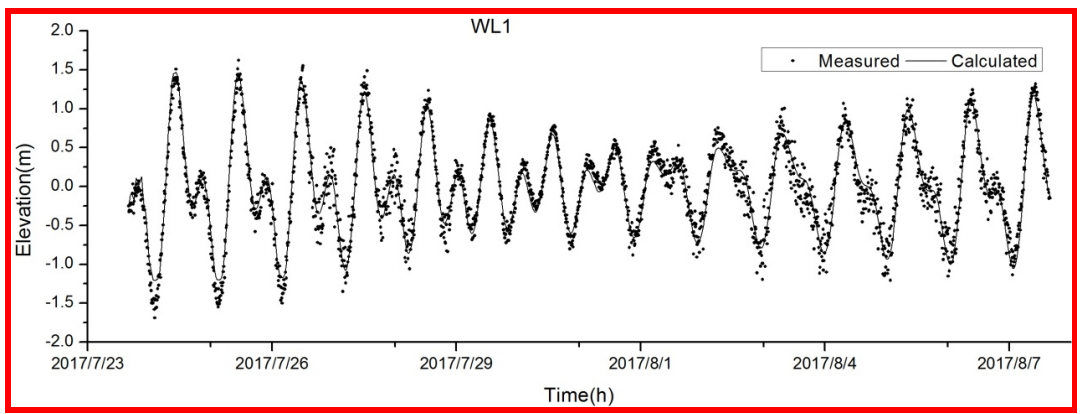

Fig. 7 Comparison Results of 15 days tide level at WL1

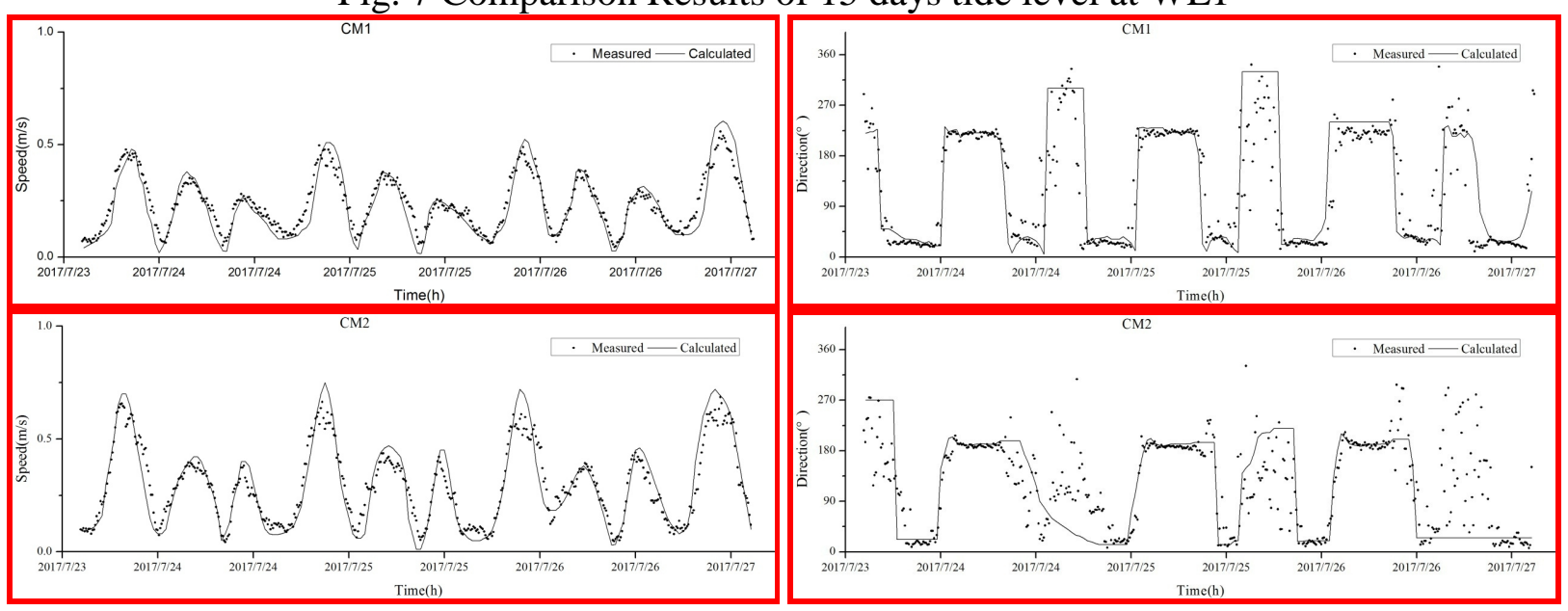

Fig. 8 Comparison Results of Current in Spring Tide at CM1\&CM2 

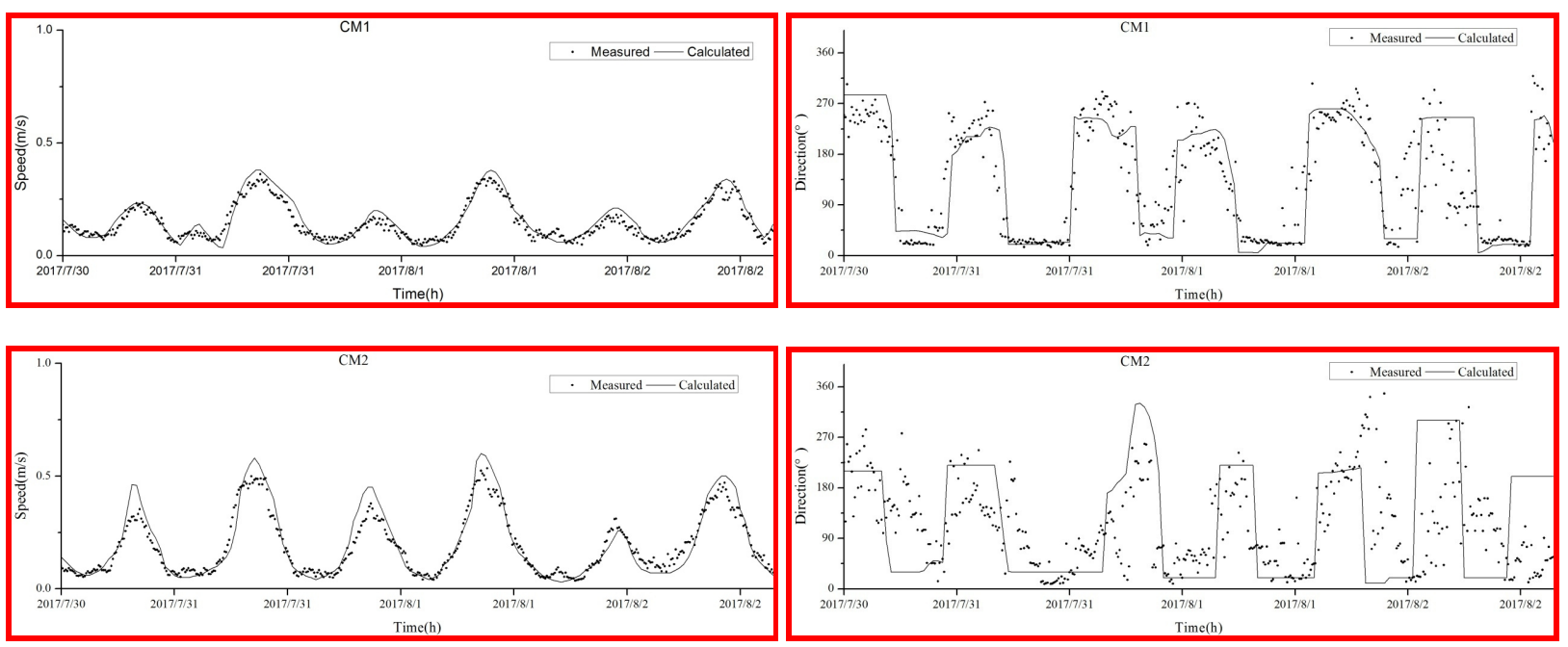

Fig. 9 Comparison Results of Current in Neap Tide at CM1\&CM2

\section{Test Results for Current}

The flow field has the following characteristics:

(1) The dominant current direction in project area is SW-NE under the effect of well-distributed flood tide from open sea.

(2) The velocity can reach $0.15 \mathrm{~m} / \mathrm{s}$ in spring tide cause of deflecting flow at the connection of the turning basin and the channel.

(3) The averaged current velocity near project ranges is $0.19 \mathrm{~m} / \mathrm{s}$, hydrodynamic force from current is weak.

(4) The velocity is increased in extension wharfs, decreased in the turning basin. The velocity has little change in the channel.

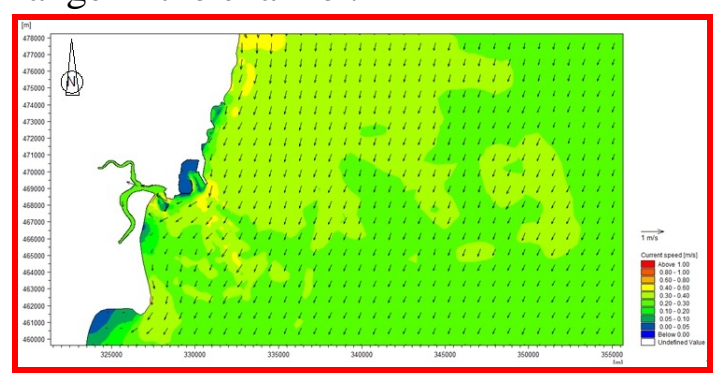

Fig. 10 The max flood current field after project

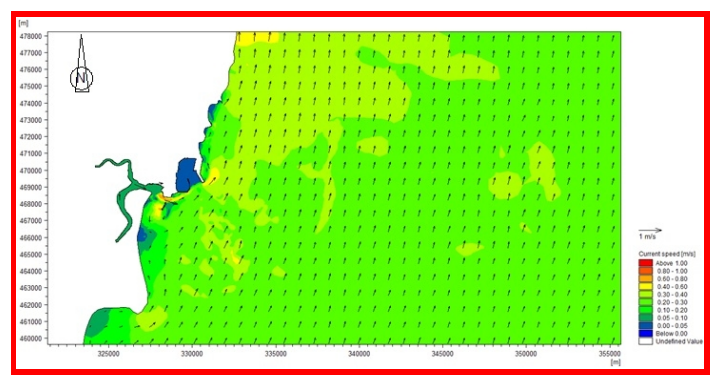

Fig. 11 The max ebb current field after project

\section{Test Results for Sediment Deposition}

Because of the extension at the east breakwater, and the greate change in water depth before and after the project, the water dynamic conditions change. The sediment environment change. The velocity is increased which makes the deposition percentage increased.

At berth district, annual deposition intensity is $0.12 \mathrm{~m} / \mathrm{a} \sim 0.30 \mathrm{~m} / \mathrm{a}$. At turning basin district, annual deposition intensity is $0.15 \mathrm{~m} / \mathrm{a}$. The annual deposition intensity is bigger in the channel, around $0.31 \mathrm{~m} / \mathrm{a}$ to $0.42 \mathrm{~m} / \mathrm{a}$.

At berths district, average annual deposition volume is about $0.67 \mathrm{~m}^{3} / \mathrm{a}$, at the turning basin district, average annual deposition volume is about $6.40 \mathrm{~m}^{3} / \mathrm{a}$, and at the channel the average annual deposition volume is $27.86 \mathrm{~m}^{3} / \mathrm{a}$. 


\section{References}

[1] Kuai Yu, TAO Jian-feng, ZHANG Qing, ZHANG Chang-kuan. Numerical Simulation on the Tidal Current and Sediment for the Yongjiang River and out sea area. Port \& Waterway Engineering, (2017), p. 59-67.

[2] JAMBI INDONESIA COMPREHENSIVE INTERNATIONAL PORT 2D CURRENT-SEDIMENT NUMERICAL MODEL RESEARCH. Tianjin Research Institute for water transport Engineering, (2017). 